\title{
Implementation of the Integrated Approach in Different Types of Exposure Scenarios
}

\author{
D. Copplestone ${ }^{\mathrm{a}}$, G. Hirth ${ }^{\mathrm{b}}$, M. Johansen ${ }^{\mathrm{c}}$, E. Lazo ${ }^{\mathrm{d}}$, J. Takala ${ }^{\mathrm{f}}, \mathrm{K}$. \\ Sakai $^{\mathrm{g}}$, T. Yankovich ${ }^{\mathrm{h}}$ \\ ${ }^{a}$ Faculty of Natural Sciences, University of Stirling, UK; e-mail: david.copplestone@stir.ac.uk; \\ ${ }^{b}$ Australian Radiation Protection and Nuclear Safety Agency, Australia \\ ${ }^{c}$ Australian Nuclear Science and Technology Organisation, Australia \\ ${ }^{d}$ OECD Nuclear Energy Agency, France \\ ${ }^{f}$ Cameco Corporation, Canada \\ ${ }^{8}$ Tokyo Healthcare University, Japan \\ ${ }^{h}$ IAEA, Austria
}

Accepted for publication in Annals of the ICRP published by SAGE. Copyright International Commission of Radiological Protection

\begin{abstract}
The ICRP recognises three types of exposure situations (planned, existing and emergency). In all three situations, the release of radionuclides into the natural environment leads to exposures of non-human biota, as well as the potential for exposures of the public. This paper describes how the key principles of the ICRP system of radiological protection apply to non-human biota and members of the public in each of these exposure situations. Current work in this area within ICRP Task Group (TG) 105 is highlighted. For example, how simplified numeric criteria may be used in planned exposure situations that are protective of both the public and non-human biota. In emergency exposure situations, the initial response will always be focused on human protection however, understanding the potential impacts of radionuclide releases on non-human biota will likely become important in terms of communication as governments and the public seek to understand the exposures that are occurring. For existing exposure situations, we need to better understand the potential impacts of radionuclides on animals and plants especially when deciding on protective actions. Understanding the comparative impacts from radiological, non-radiological and physical aspects is often important in managing remediating legacy sites. The TG is making use of case studies of how exposure situations have been managed in the past to provide additional guidance and advice for the protection of non-human biota.
\end{abstract}

Keywords: Radiological protection; Environmental protection; Exposure situations; Non-human biota

\section{INTRODUCTION}

The International Commission on Radiological Protection (ICRP) is working towards integrating the approaches taken for radiological protection of humans and the environment to fully meet the recommendations set out in Publication 103 (ICRP, 2007). Task Group (TG) 105 on 'Considering the Environment when Applying the System of Radiological Protection' has been set up to build on the approaches outlined in ICRP Publication 124 (ICRP, 2014) and to use case studies to illustrate how the radiological protection principles of justification and optimisation can be applied apply in the context of protection of both humans and the environment under the three exposure situations recognised by ICRP (2014):

- Planned exposure situations - "exposure situations resulting from the operation of deliberately introduced sources. Planned exposure situations may give rise to exposures that are anticipated to occur (normal exposures) and exposures that are not anticipated to occur" (potential exposures). 
- Emergency exposure situations - "exposure situations resulting from a loss of control of a planned source, or from any unexpected situation (e.g. a malevolent event), that requires urgent action in order to avoid or reduce undesirable consequences".

- Existing exposure situations - "exposure situations resulting from sources that already exist when a decision to control them is taken".

In Publication 108 (ICRP, 2008), a schematic approach to the protection of both humans and the environment in relation to the three exposure situations was presented (Fig 1) which demonstrated how the system of radiological protection can be integrated in support of decision-making to ensure human and environmental protection. For example, while radiological protection for humans is subject to the application of dose limits, constraints and reference levels according to the exposure situation; for the environment, there are 12 Reference Animals and Plants (RAPs) that have been used to define numeric criteria (Derived Consideration Reference Levels (DCRLs)). DCRLs are defined as "a band of dose rate within which there is likely to be some chance of deleterious effects of ionising radiation occurring to individuals of that type of Reference Animal or Plant, derived from a knowledge of defined expected biological effects for that type of organism that, when considered together with other relevant information, can be used as a point of reference to optimise the level of effort expended on environmental protection, dependent upon the overall management objectives and the exposure situation".

While the dose criteria are expressed differently for humans and the environment, their use within the system of radiological protection has the same purpose, namely to aid decision making on the appropriate level of protection to apply for both humans and the environment, while also addressing the fundamental ethical principle of doing more good than harm (ICRP, 2014). That said, it is recognised that applying all of these dose criteria when carrying out dose assessments and deciding on the implementation of a protection strategy, is highly dependent upon factors such as the exposure situation and its prevailing circumstances, relevant endpoints for the management processes and non-radiological factors. It is the aim of TG105 to explore these issues further to enable us to provide advice and recommendations on how to implement an integrated approach to radiological protection. The initial approach being considered for each exposure situation is outlined below.

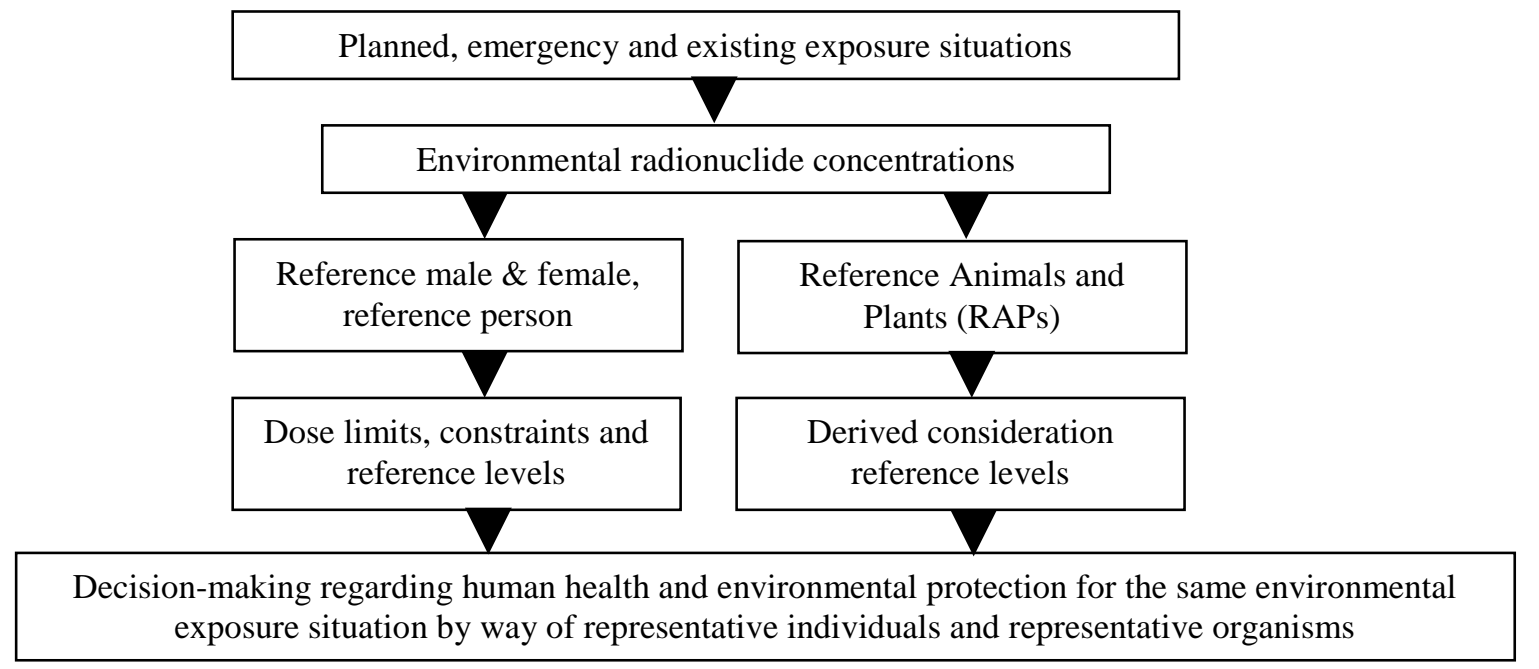

Fig. 1. Schematic approach to the protection of both humans and the environment in relation to any exposure situation (ICRP, 2008). 


\section{PLANNED EXPOSURE SITUATIONS}

In Publication 124 (ICRP, 2014) the Commission recommended that, for planned exposure situations, the lower boundary of the relevant DCRL band should be used as the appropriate reference point for the protection of the different types of non-human biota within a given area during the planning of controls to a source. It was also noted that cumulative impacts from multiple sources may need to be considered depending upon the prevailing circumstances being assessed. The concept here seems reasonable - that we should not 'plan' protection that could potentially lead to harm to non-human biota in just the same way as we aim to prevent harm to humans bearing in mind that the DCRL represents a 'band of dose rate' within which there is some chance of deleterious harm occurring. In practice, however some of the DCRL bands are set on a precautionary basis due to lack of biological effect data in the literature and this may lead to issues in the practical implementation of the approach. Task Group 99 is currently reviewing and updating the basic data underpinning the derivation of the DCRLs and has developed new approaches that could be used to refine DCRLs which may address this problem.

In practice there should be few, if any, occasions where planned exposure situations are likely to lead to situations where the protection of the environment/non-human biota is potentially compromised and additional protective measures are warranted. The emphasis here instead is usually on demonstrating that the environment can be considered protected. Furthermore, the exposure pathways for non-human biota and humans in the environment are likely to be similar, e.g. inhalation of (re)suspended contaminated particles or gaseous radionuclides, contamination of external layers such as skin, fur or hair, ingestion of contaminated food/prey/plant material/water, external exposure from contaminated surfaces (e.g. soil) or immersion in a plume of radioactive materials. However, to be able to show in a simplified and consistent manner that both humans and the environment are protected, it should be possible to back-calculate environmental media activity concentrations based on human dose criteria (e.g. the $1 \mathrm{mSv}$ dose limit or a suitable dose constraint for a site or source) and the appropriate reference criteria for the RAPs using the DCRLs as suggested above. Selecting the most restrictive of these environmental criteria, whether from the human or RAP calculations, would then demonstrate protection of both humans and the environment. This approach has been carried out already by the International Atomic Energy Agency (IAEA) for the London Convention (IAEA, 2015) and the OSPAR Commission (IAEA, 2013a).

The back-calculated values are termed Environmental Assessment Criteria and their generation is an example of an integrated assessment (OSPAR, 2016). It should be noted, however, that it is assumed the source of the human food stuffs (e.g. fish) coexist in the same locations as the non-human biota being used to estimate the environmental doses.

The above approaches are also consistent with the IAEA Safety Standards (IAEA, 2014) which set out that the protection of humans and the environment (in terms of non-human biota and resources) for the present and in the future, should be protected in an integrated manner.

There are dose assessment tools that can be used for conducting human dose assessments for planned exposure situations (e.g. PC Cream (Smith and Simmonds, 2015) and the RESRAD-suite of codes (Argonne National Laboratory, 1997)) and non-human biota (e.g. ERICA (Brown et al., 2016), RESRAD-biota (USDOE, 2002)). Furthermore, there are now tools that have been designed to consider humans and wildlife in an integrated manner (e.g. CROMERICA (Mora et al., 2015) and the planned updates to the SRS-19 models (Yankovich et al. 2014)). These latter tools are useful because they address one of the most common shortcomings of the individual human/non-human biota tools as they use the same source term input. In all cases, however, we need to recognise that there are likely to be circumstances 
where humans and non-human biota are exposed in different places by different sources. In these circumstances an "integrated approach" needs to take both aspects under consideration.

To address these points, TG105 is planning to work with the IAEA to consider planned exposure situation scenarios such as the radioactive discharges from hospitals, nuclear power plants and other types of facilities to investigate what can be learned from the integration of human and non-human biota assessments.

\section{EMERGENCY EXPOSURE SITUATIONS}

In emergency exposure situations, communication of possible radiological effects is key and, while priority needs to be focused on the protection and safety of humans in the event of an emergency, experience has shown that in such situations, questions regarding the state of the environment may also arise. Therefore, being able to say something on the implications of an emergency on the environment more generally could be useful. Fig 2 shows the approach of using severe-effect reference levels that was described in Publication 124 (ICRP, 2014). The concept of a severe-effect reference level is often used in the chemical industry and ICRP (2014) defined this as "approximately equivalent to a band of doses two orders of magnitude above the DCRL band". These severe-effect reference levels may be used during the initial phase of the emergency to predict effects on non-human biota. Over time, as the radioactivity levels decline through radioactive decay, particularly of short lived radionuclides, or through management action, it is also possible to predict the changing impact on non-human biota. However, improved and more detailed communication is not the only possible outcome of integrating the environment into the system of radiological protection for emergency exposure situations.

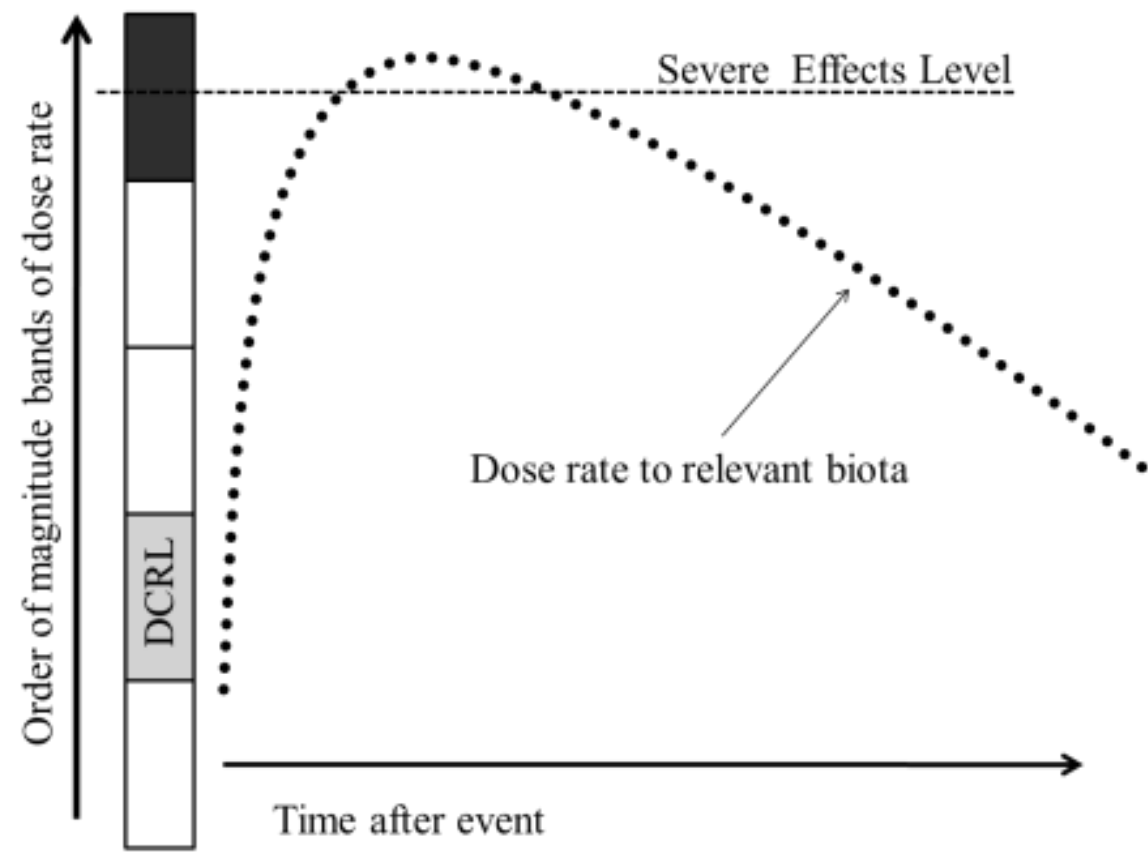

Fig. 2. Potential use of severe-effects bands, relative to Derived Consideration Reference Levels, to relate exposure of non-human biota following an accidental or emergency release of radionuclides into the environment (ICRP, 2014).

Better integration of the environmental considerations into protective-action decisions may lead to early consideration of the environment in, for example, better planning in the longer term regarding where to place new facilities from the point of view of potential radiological impacts on non-human biota or incorporating radiological considerations in the emergency 
preparedness planning and in the potential longer-term recovery options that might be applied. This approach should integrate and embed thinking about environmental protection issues as part of the optimisation for protection under all circumstances from the start of planning new facilities and uses of radioactive materials.

To explore these issues, the TG will evaluate past accidents (e.g. Chernobyl and Fukushima) and using a systematic review approach consider whether impact on the environment was included in decision-making.

\section{EXISTING EXPOSURE SITUATIONS}

Existing exposure situations may occur following a nuclear or radiological emergency, or from the presence of historic contamination, past industrial practice (legacy sites, (IAEA, 2002, IAEA 2014)) or as a result of naturally occurring radioactivity. The key point with existing exposure situations is the need to make a decision to bring the situation under improved radiological management based on the contamination levels and the associated radiation exposure (IAEA, 2014, ICRP, 2007). There are a range of protective actions for existing exposure situations that will optimise radiological protection. In the past, these options have primarily focused on optimising protection for humans and there are examples where, in doing this, the ethical principle of doing more good than harm has not been adhered to with respect to demonstration of protection of the environment and non-human biota. Therefore, integrating environmental protection into the decision-making process should therefore help to ensure that consideration will be given to the impacts on non-human biota It should be noted that there are several aspects that should be considered for example:

- the radiological assessments (before and after remediation) of the exposure of humans and non-human biota (bearing in mind that the non-human biota may be present at the site for longer periods of time than humans);

- the area being impacted (and therefore the size of the potentially affected populations of non-human biota that may be of interest at the site);

- the presence of non-radiological hazards that might need to be addressed;

- the consequences and impacts of the current situation and after the potential controls are put in place.

Copplestone et al. (2016) explored several case studies to determine what might happen when considering the environment and more specifically, non-human biota, in existing exposure situations for different approaches. On the basis of the evaluations conducted several key points arose: 1) the international guidance on the remediation of areas with residual contamination was unclear and that further technical and practical guidance should be developed (IAEA, 2013b); 2) that decision-making with regard to existing exposure situations can be strongly influenced by the prevailing circumstances, public opinion, legal and political constraints; 3) that there are situations where the non-human biota are likely to be more impacted than humans, by the radiological situation and/or the remediation plans; 4) the use of DCRLs could usefully inform decisions especially with regard to the consequences of different protective actions, although each situation needs to be examined on a case-by-case basis. However, some uncertainties still remain:

- What should be done if the assessments suggest impacts above the DCRLs but there is no significant impact on humans?

- How should multiple hazards (e.g. radiological, non-radiological and physical in nature) be considered?

- How can the DCRLs be applied effectively within the optimisation of radiological protection? 
The last bullet point is important, bearing in mind that the overall aim is to achieve ALARA (as low as reasonably achievable) with consideration of social and economic costs. The key now is to consider how the environment should be included alongside social and economic costs as indicated Publication 111 (ICRP, 2009). TG105 will use different case studies to evaluate what has happened in the past, to address the 'What if' questions to determine if different decisions might have been made had the environment and non-human biota specifically been considered. These evaluations will be undertaken using a systematic review and through discussions with people who are/were involved in the decision-making processes regarding the case study sites.

\section{CONCLUSIONS}

A number of potential case studies covering the three exposure situations have been identified including those already described in Copplestone et al. (2016) (Andreeva Bay waste storage site remediation, Little Forest radioactive waste burial ground, impact of Mayak releases along the Techa river). Additionally we will be looking at the radium and uranium contaminated sites (at Winterbeek in Belgium, Gunnar and Midwest uranium mine and mill sites), former weapons testing sites (e.g. Maralinga, Montebello Islands and the Marshall Islands) and areas affected by past accidents (Chernobyl and Fukushima). These case studies will be used to explore the questions raised above.

We will be collating information on these case studies using a systematic review approach and then exploring the decision-making approaches that were undertaken, investigate how much the environment was considered, the social and cultural values of the environment, how values were placed on the environment and looking at the consequences for the environment of the recommended recovery strategies adopted. Some of the above case studies have had recent non-human biota assessments conducted which suggest that the non-human biota might be more exposed than humans, possibly as a consequence of the way people are using the sites. Other case studies contain non-radiological hazards (e.g. chemical contamination) or where the recovery strategy has the potential to cause significantly more harm to the environment than the radiological contamination.

We will generate advice and recommendations for further integrating the environment into decision-making for radiological protection, by incorporating fundamental ethical principles such as "do more good than harm".

\section{REFERENCES}

Argonne National Laboratory, 1997. Developing the RESRAD Family of Computer Codes for Environmental Risk Assessment. Environmental Assessment Division. Available at http://resrad.evs.anl.gov/docs/anlrares.pdf [last accessed 28-09-2017]

Brown J.E., Alfonso B., Avila R., Beresford N.A., Copplestone D., Hosseini A., 2016. A new version of the ERICA tool to facilitate impact assessments of radioactivity on wild plants and animals. J. Environ. Radioact. 153, 141-148.

Copplestone D., Larsson C-M., Strand P., Sneve M.K., 2016. Protection of the environment in existing exposure situations. In: Proceedings of the Third International Symposium on the System of Radiological Protection. Ann. ICRP. 45(1S).

IAEA, 2002. Radiation Legacy of the 20th Century: Environmental Restoration. IAEA TECDOC 1280. International Atomic Energy Agency, Vienna.

IAEA, 2011. General Safety Requirements (GSR) Part 3: Radiation Protection and Safety of Radiation Sources: International Basic Safety Standards, Vienna. 


\section{ICRP 2017 Proceedings}

IAEA, 2013a. Definition of Radiological Environmental Assessment Criteria for the OSPAR Convention: A Proposal by the IAEA for consideration by the RSC - IAEA Contribution to RSC 2013. Ref. RSC 13/7/1.

IAEA, 2013b. Report of an International Expert Meeting on Decommissioning and Remediation after a Nuclear Accident. International Atomic Energy Agency, Vienna.

IAEA, 2014. Radiation Protection and Safety of Radiation Sources: International Basic Safety Standards. IAEA Safety Standards Series GSR Part 3. International Atomic Energy Agency, Vienna.

IAEA, 2015. Determining the Suitability of Materials for Disposal at Sea under the London Convention 1972 and London Protocol 1996: A Radiological Assessment Procedure. IAEA Techdoc No. 1759. 96pp.

ICRP, 2007. The 2007 Recommendations of the International Commission on Radiological Protection. ICRP Publication 103. Ann. ICRP 37(2-4).

ICRP, 2008. Environmental protection - the concept and use of Reference Animals and Plants. ICRP Publication 108. Ann. ICRP 38(4-6).

ICRP, 2009. Application of the Commission's Recommendations to the Protection of People Living in Long-term Contaminated Areas after a Nuclear Accident or a Radiation Emergency. ICRP Publication 111. Ann. ICRP 39 (3).

ICRP, 2014. Protection of the environment under different exposure situations. ICRP Publication 124. Ann. ICRP 43(1).

Mora J.C., Cortes D., Robles J., Rodriguez C., Diaz A., Sanchez A., Brown J.E. Beresford N.A., Steiner M., 2015. CROMERICA: a unique tool to perform dose assessments for human and wildlife. In: Proceedings of the STAR final dissemination event, Aix-en-Provance, 9-11 June 2015.

OSPAR Commission, 2016. Agreement on a Methodology for Deriving Environmental Assessment Criteria and their application. OSPAR Agreement 2016-07. Available from https://www.ospar.org/documents?v=35461 (Last accessed 28-09-2017).

Smith J.G. and Simmonds J.R., 2015. The Methodology for Assessing the Radiological Consequences of Routine Releases of Radionuclides to the Environment Used in PC-CREAM 08. Health Protection Agency Report. HPA-RPD-058. 295pp.

USDOE, 2002. A Graded approach for evaluating radiation doses to aquatic and terrestrial biota. Technical standard DOE-STD-1153-2002, Modules 1-3, United States Department of Energy, Washington D.C.

Yankovich T.L., Proehl G., Tellera D., Berkovskyy V. 2014. Generic Screening Models for Assessing Exposures to the Public and ICRP Reference Animals and Plants. In: the $3^{\text {rd }}$ International Conference on Radioecology and Environmental Radioactivity. Barcelona, 7-12 ${ }^{\text {th }}$ September 2014. 